\title{
Safer and Precise Replant Osteosynthesis with the T-Ring Digital Tourniquet
}

\author{
Dimitris Reissis, MBBS, BSc (Hons), PGDip (MedEd) ${ }^{1}$ \\ 1 Department of Plastic and Reconstructive Surgery, St Thomas' \\ Hospital, London, United Kingdom \\ 2 Department of Plastic and Reconstructive Surgery, Queen Victoria \\ Hospital, East Grinstead, United Kingdom
}

J Reconstr Microsurg Open 2016;1:71-72.

Digital replantation is now a routine procedure for many hand surgery units. ${ }^{1}$ Skeletal shortening is important to allow the direct repair of structures in replantation. Good alignment can be technically challenging; however, time spent securing optimal osteosynthesis will make the subsequent steps far easier. ${ }^{2,3}$ We describe a technical tip that can allow for safer and more precise skeletal shortening.

A 29-year-old male forestry worker presented with a combination of degloved, crush, and avulsion amputations sustained at work to his right dominant fingers. The resulting metacarpal hand (sparing the thumb) had only the middle finger suitable for salvage as a heterotopic replantation to the index finger stump.

The T-Ring (Precision Medical, Thousand Oaks, CA) digital tourniquet has a rigid plastic radiolucent ring supporting a silicone diaphragm with a central hole. This is usually applied over the finger as a low pressure $(150-165 \mathrm{~mm} \mathrm{Hg}$ ) digital tourniquet. ${ }^{4}$ For this case, the tourniquets were applied over the proximal and distal bone ends as a combined soft tissue retractor and protector retained by stitches. This is very stable and is self-supporting, so the operator or assistant does not need to hold these retractors, thereby reducing interference and sharps injury potential.

Shortening of the index finger proximal stump and the middle finger proximal phalanx was necessary to normalize the bone length discrepancy, and was easy and safe to perform with this retractor variant. The T-Ring can also act as an alignment guide while performing the saw cut which cannot be achieved with a latex glove (-Fig. 1). This retraction method is also of great benefit during the 90-90 wire osteosynthesis, providing a clear view with no chance of tissue entanglement during drilling or wiring (-Fig. 2).

After completion of the osteosynthesis, the tourniquet can be removed atraumatically by snapping the plastic ring at two specially weakened points ( $\boldsymbol{- F i g . 1}$ ) and the silicon component is cut with scissors for full release. Correcting the digit

received

March 9, 2016

accepted after revision

April 3, 2016

published online

May 20, 2016

\author{
Dariush Nikkhah, MSc, MRCS ${ }^{2}$ Duncan Bayne, FRCS²
}

Address for correspondence Dariush Nikkhah, MSc, MRCS, Department of Plastic and Reconstructive Surgery, Queen Victoria Hospital, Holtye Road, East Grinstead, United Kingdom, RH19 3DZ (e-mail: dariushnikkhah@hotmail.com).

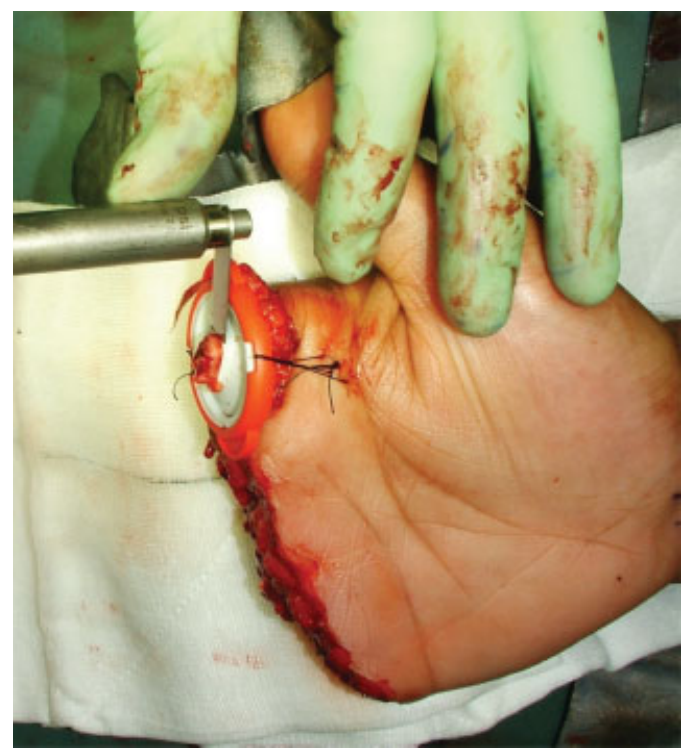

Fig. 1 The T-Ring positioned over the proximal bone stump retracting the soft tissue and helping align the saw cut. The sutures have been placed around the weakened "break point" of the ring.

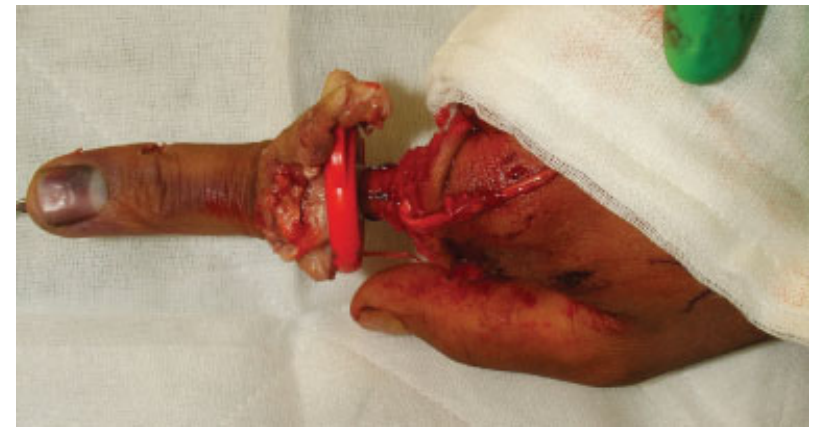

Fig. 2 After completion of 90-90 wiring and proximal T-Ring removal, the exposure and protection is demonstrated distally without sutures.

Copyright $\odot 2016$ by Thieme Medical Publishers, Inc., 333 Seventh Avenue, New York, NY 10001, USA. 
length ensured that plenty of tissue was available for tensionfree anastomosis and soft tissue closure.

The T-Ring can be repositioned proximally as a digital tourniquet for the remaining replantation procedures as this is a low-pressure tourniquet; however, the authors do not favor this to avoid potential pressure stress on the digital vessels. The remainder of the replantation was routine with no adverse events during the recovery and the patient was discharged from hospital to outpatient rehabilitation 5 days postoperatively.

\section{References}

1 Soucacos PN. Indications and selection for digital amputation and replantation. J Hand Surg [Br] 2001;26(6):572-581

2 Morrison WA, McCombe D. Digital replantation. Hand Clin 2007; 23(1):1-12

3 Nikkhah D, Sadr AH, Murugesan L, Konczalik W, Rodrigues J. Crossclamping of bony stumps in preparation for osteosynthesis in digital replantation. Microsurgery 2016 (e-pub ahead of print). doi:10.1002/micr.30035

4 Lahham S, Tu K, Ni M, et al. Comparison of pressures applied by digital tourniquets in the emergency department. West J Emerg Med 2011;12(2):242-249 